\begin{tabular}{|c|c|c|}
\hline $\begin{array}{l}\text { GEOSPORT } \\
\text { SOCIETY }\end{array}$ & $\begin{array}{c}\text { GEOSPORT FOR SOCIETY } \\
\text { Scientific Journal founded in } 2014 \text { under aegis of University of Oradea (Romania), } \\
\text { University of Debrecen (Hungary), University of Gdánsk (Poland) }\end{array}$ & EDTTURA UNIVERSITITTIII \\
\hline & $\begin{array}{c}\text { ISSN 2393-1353 } \\
\text { Edited by Oradea University Press } \\
\text { 1, University Street, 410087, Oradea, Romania }\end{array}$ & \\
\hline 5 & Journal homepage: http://geosport.uoradea.ro & \\
\hline
\end{tabular}

\title{
Testing the visual-motor coordination and reaction speed in children aged between 10-14 years old
}

\author{
Dan Alexandru SZABO1* ${ }^{*}$, Andreea Roxana UJICĂ ${ }^{1}$, Ovidiu URSU²
}

1. George Emil Palade University of Medicine, Pharmacy, Science, and Technology, Romania, Str. Gheorghe Marinescu, No. 38, Târgu Mureș, Romania, e-mail: dan-alexandru.szabo@umfst.ro, roxiuji23@gmail.com

2. Brateiu Secondary School, Romania, Str. Principală, No. 68, Brateiu, Romania, e-mail: ovidiuursu1212@gmail.com

* Corresponding author

Citation: Szabo, D.A., Ujică, A.R., \& Ursu O. (2021). Testing the eye-hand coordination and reaction speed in children aged between 10-14 years old. Geosport for Society, 15(2), 110-121. https://doi.org/10.30892/gss.1505-077

Article history: 11.10.2021; Revised: 30.11.2021; Accepted: 15.12.2021, Available online: 20.12.2021

\begin{abstract}
The present study aimed to debate a topic less addressed by most people, which involved research on a group of 20 students from rural areas, aged 10-14 years, which consists of performing two tests, namely the Ruler drop test and the Hand-eye coordination test, which aims at the reaction speed of the dominant and non-dominant hand and also the hand-eye coordination capacity of the subjects. The paper aimed to identify whether somatic factors and age influence the results of the group. In order to perform the two tests, it was necessary, for the beginning, information related to the study group, information on weight, age, height, dominant hand, respectively dominant eye. These represented the point of interest of the research, being reported individually to the test results, thus constituting the study basis of statistics. After obtaining the results, we concluded that a significant significance is encountered when comparing the dominant hand with the non-dominant one, obtaining a positive value for the dominant hand. At the same time, we interpreted after the research that females tend to have a much faster reaction speed, more significant than the males when it comes to using the non-dominant hand. The hypothesis was confirmed, with differences in somatic factors' influence, but the others do not show significant values except those stated above. In addition to the practical part, the research involves an interesting theoretical foundation being reached aspects related to proprioception, coordination, speed, ways of using tests, and the opinion of other researchers who have conducted similar studies.
\end{abstract}

Keywords: visual-motor coordination, reaction speed, proprioception, physical education and sport

\section{Introduction}

Proprioception was first defined by neuropsychologist Charles Sherrington in the early $20^{\text {th }}$ century. The study concluded that in the body, there are specific receptors in the musculoskeletal system in which different stimuli are triggered by 
changes in the body that are perceived in space, depending on the position of the physique, limbs, and connection with the layer. He argued that the body triggers stimuli to receptors, so he called this area of sensory perception the proprioceptive field. Sherrington defined proprioception as the perception of the position and movement of joints, and the body in space is, in fact, very close to the current understanding of proprioception (Kim, 2001).

Proprioception can be defined in a variety of ways. Proprioception is now described as an organism's ability to detect the location and movement of joints and the perception of spatial forces (Lephart et al., 1997). It is the whole neural input from mechanoreceptors into the central nervous system (Myers et al., 1999).

Proprioception plays a crucial role in planning accurate and concerted motions, maintaining balance, and managing body position. It also affects sports learning and re-education (Westlake and Culham, 2007).

Understanding the body parts in space is essential for effective communication with the environment (Riemann and Lephart, 2002). The importance of proprioception is evident in all fields. In sports, proprioception plays a vital involvement in trauma preventive and rehabilitation. The role of proprioception increases with the aging of the population, especially in the case of falls. With age, proprioception is also affected, including other functions, resulting in a poor perception of the body's position in space. Decreased proprioception can alter the limb's joint biomechanics and neuromuscular regulation, leading to impaired balance and a greater likelihood of falls (Ribeiro and Oliveira, 2007).

With age, the deterioration of the proprioceptive mechanism involves changes in the peripheral and central nervous systems. Due to changes in proprioception, the biomechanics of the joints and the neuromotor regulation of the limbs change, leading to balance disorders. Proprioceptive function declines in the elderly procedure that is related to balance defects. Poor balance and proprioception boost the probability of collapses (Ribeiro and Oliveira, 2007). Many authors (Erickson, 2007; Ellison, 2015) describe the eye-hand vision-motor reaction time as a series of decisions to complete a specific task and the resulting movement (Szabo et al., 2020). The eye-hand vision-motor reaction time represents integrating visual information, perception-based decision-making, and movement to complete a specific task (Laby et al., 2018). Eye-hand coherence is the capability of the visual process to supervise the knowledge obtained throughout the eyeballs to manage and guide the thinking of the hand to complete a given task (such as writing or capturing a ball) (Singh, 2010). Hand-eye collaboration is one of the skills required by humans and can affect all aspects of daily life, including school, daily life activities, and social interaction (Bakhtiar et al., 2018).

Proprioceptive control has long been essential for improving sports performance, medical disorders, everyday life activities, or further sports performance. Some specialists associated the proprioceptive control with somatosensory or proprioceptive deficiencies with effects on movement regulation that can develop from early ages (Coleman et al., 2001; Goble et al., 2009; Zwicker et al., 2013; Li et al., 2015), is linked with a low level of movement and sports practice (Szabo et al., 2021). These capacities were associated with the sense of relative 
location and movement of the limbs and body (Konczak, 2009) and needed in any human activity. Other proprioceptive control viewpoints emphasize the viewpoint of mechanoreceptors in joints, muscles, tendons, and skin (Holst-Wolf et al., 2016) provide proprioceptive information. Also, other studies highlight the importance of balance in developing proprioception skills (Sopa and Pomohaci, 2021).

\section{Methods of research}

The research used two different tests for assessing hand-eye coordination, the alternate-hand wall toss test, and the ruler drop test.

The hand-eye coordination test (Mackenzie, 2009)

A hand-eye coordination test is an assessment tool for hand-eye coordination. Participants throw a ball against the wall with one hand during axillary movements and try to catch it with the other hand.

Purpose: To measure hand-eye coordination

Equipment required Tennis or baseball, smooth and solid wall, marking belt, stopwtch (optional)

Pre-test: Explain the test procedure to the subject. Carry out health risk screening and obtain informed consent. Prepare a form and record basic information such as age, height, weight, gender, and test conditions. Perform proper warm-ups and exercises. View more detailed information about the pre-test procedure. Procedure: Place a mark at a certain distance from the wall (for example, 2 meters, 3 feet). This person is standing behind the line, facing the wall. The ball was thrown towards the wall in an underarm motion from one hand and tried to catch it with the other hand. Then throw the ball back to the wall and catch it with the original hand. The test can continue for a specified number of attempts or a set period (for example, 30 seconds). By increasing the fixed-term constraint, the factor of work stress is also increased.

Scoring: This table lists the general scores of the wall throw test based on the number of successful catches in 30 seconds.

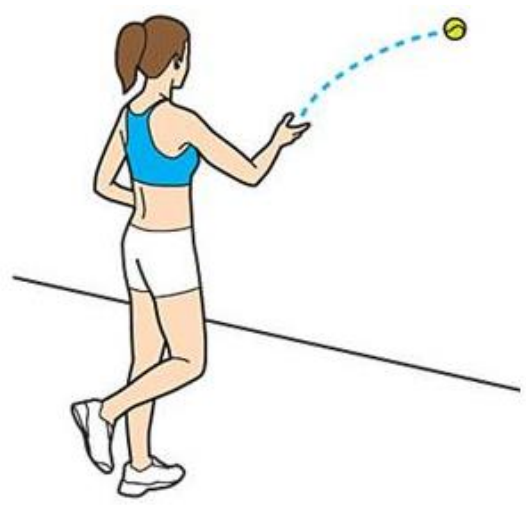

Figure 1. The hand-eye coordination test 1

1 https://nathankanginanpdhpeassignment.weebly.com/hand-wall-toss.html 
Table 1. Scoring scale for the hand-eye coordination test ${ }^{2}$

\begin{tabular}{|c|c|}
\hline Rating & Score (in 30 seconds) \\
\hline Excellent & $>35$ \\
\hline Good & $30-35$ \\
\hline Average & $20-29$ \\
\hline Fair & $15-19$ \\
\hline Poor & $<15$ \\
\hline
\end{tabular}

The ruler drop test (Mackenzie, 2004)

The goal of this test is to time athletes' response times.

Resources required

You will need the following items to complete this test:

-Assistant -Meter stick

The assistant places the ruler between the athlete's dominant hand's outstretched index finger and thumb, flushing the top of the athlete's thumb with the ruler's zero centimeter line (Davis et al., 2000). When the ruler is released, the aide instructs the athlete to grab it as soon as possible.

The athlete grips the ruler with his index finger and thumb as soon as the helper loosens it. The assistant detects the measurement between the bottom of the ruler and the top of the athlete's thumb, the position of the ruler is taken. The test is repeated twice, and the mean value is evaluated in evaluation. The following standard data can be used for this test.

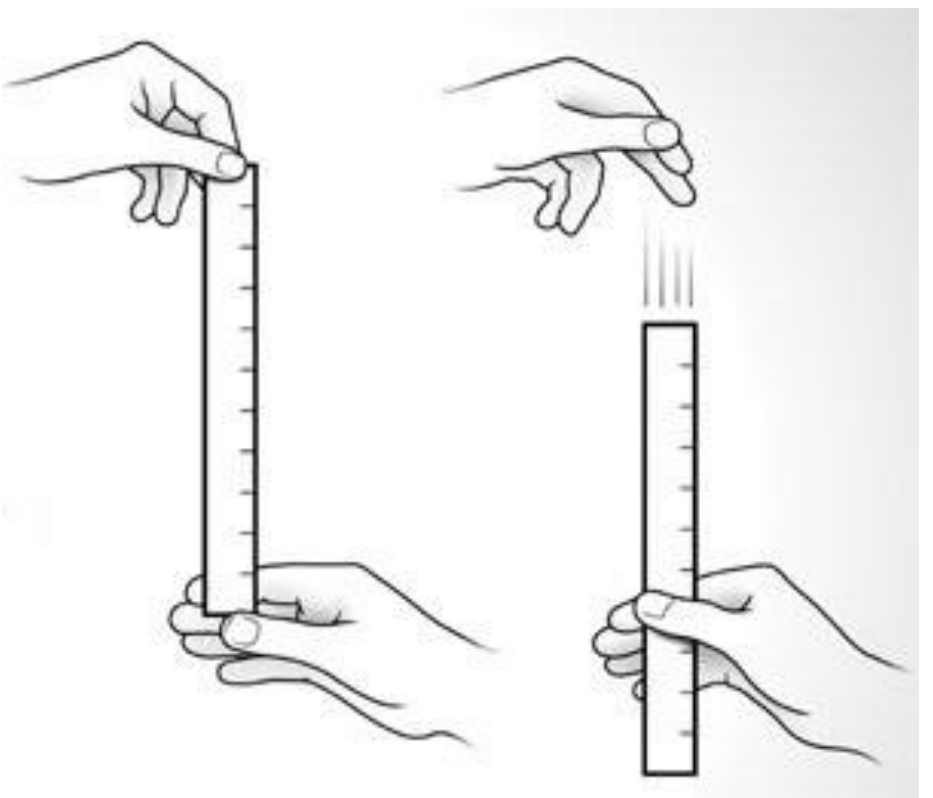

Figure 2. Ruler drop test protocol ${ }^{3}$

2 https://www.topendsports.com/testing/tests/wall-catch.htm

3 http://math.oxford.emory.edu/site/home/futurePages/excelProjectReactionTime/ 
Table 2. Scoring scale for ruler drop test 4

\begin{tabular}{|c|c|}
\hline Rating & Score (in 30 seconds) \\
\hline Excellent & $<7.5 \mathrm{~cm}$ \\
\hline Above average & $7.5-15.9 \mathrm{~cm}$ \\
\hline Average & $15.9 \mathrm{~cm}-20.4 \mathrm{~cm}$ \\
\hline Below average & $20.4 \mathrm{~cm}-28 \mathrm{~cm}$ \\
\hline Poor & $>28$ \\
\hline
\end{tabular}

\section{Study Design and Subjects}

The research hypothesized that there is a significant difference between reaction speed and hand-eye coordination in children of different ages due to age and morphological characteristics such as height, sex and weight. The objective of the research was to monitor the ability of children to visually transmit the information received in order to control, guide and direct their hands when catching a ball (hand-eye coordination). To achieve this goal, it is necessary to identify the dominant eye and hand. A second objective of the study was to determine the reaction time of the students with the help of the drop test of the rule, to observe the speed differences and to compare the dominant hand with the non-dominant hand. The study site was Lunca Bradului secondary school with boys aged 10-14 $(n=20)$, 11 girls and 9 boys studying at school. Subjects were asked to perform two hand-eye coordination tests, throwing the ball against the wall and catching it, and the ruler drop test to measure their ability to coordinate

\section{Statistical tests used}

For comparison of means and medians, the t-student test was applied for paired and unpaired data; respectively, the Mann-Whitney test and the Pearson test were applied to determine the correlation. The significance threshold chosen for $p$ was 0.05 . Statistical analysis was performed using the GraphPad Prism demo utility.

\section{Results}

The table below presents the group of students on whom this research was prepared, being presented their general data, respectively data that are of interest in the research.

Table 3. Subjects of the investigation

\begin{tabular}{|c|c|c|c|c|c|c|}
\hline $\begin{array}{c}\text { Subjects of the } \\
\text { research }\end{array}$ & Age & Gender & Height & Weight & $\begin{array}{c}\text { Non-dominant } \\
\text { hand }\end{array}$ & $\begin{array}{c}\text { Dominant } \\
\text { eye }\end{array}$ \\
\hline Subject 1 & 13 & $\mathrm{~F}$ & 1.50 & 40 & Right & Left \\
\hline Subject 2 & 12 & $\mathrm{~F}$ & 1.47 & 44 & Left & Left \\
\hline Subject 3 & 12 & $\mathrm{~F}$ & 1.45 & 35 & Right & Right \\
\hline Subject 4 & 13 & $\mathrm{M}$ & 1.65 & 60 & Right & Right \\
\hline Subject 5 & 12 & $\mathrm{~F}$ & 1.66 & 52 & Right & Right \\
\hline Subject 6 & 12 & $\mathrm{~F}$ & 1.61 & 54 & Right & Left \\
\hline Subject 7 & 12 & $\mathrm{~F}$ & 1.54 & 41 & Left & Left \\
\hline Subject 8 & 12 & $\mathrm{~F}$ & 1.65 & 87 & Right & Right \\
\hline
\end{tabular}

${ }^{4}$ https://www.brianmac.co.uk/rulerdrop.htm 


\begin{tabular}{|c|c|c|c|c|c|c|}
\hline Subject 9 & 14 & F & 1.64 & 52 & Right & Right \\
\hline Subject 10 & 13 & M & 1.55 & 57 & Right & Right \\
\hline Subject 11 & 13 & M & 1.60 & 42 & Right & Right \\
\hline Subject 12 & 13 & M & 1.83 & 80 & Right & Left \\
\hline Subject 13 & 13 & F & 1.55 & 45 & Right & Right \\
\hline Subject 14 & 13 & F & 1.61 & 85 & Right & Right \\
\hline Subject 15 & 13 & M & 1.58 & 45 & Right & Left \\
\hline Subject 16 & 14 & M & 1.69 & 42 & Right & Left \\
\hline Subject 17 & 13 & M & 1.68 & 60 & Right & Right \\
\hline Subject 18 & 14 & M & 1.85 & 95 & Right & Right \\
\hline Subject 19 & 14 & F & 1.62 & 57 & Right & Right \\
\hline Subject 20 & 15 & M & 1.75 & 50 & Right & Right \\
\hline Arithmetic Mean & 13 & - & 1.54 & 61.35 & - & - \\
\hline
\end{tabular}

The table below presents the results obtained after performing the two coordination and speed tests, presenting an average of the group, which is detailed below.

Table 4. The results at the two tests (hand-eye coordination test and ruler drop test)

\begin{tabular}{|c|c|c|c|c|c|}
\hline \multirow{2}{*}{$\begin{array}{l}\text { Subjects of the } \\
\text { research }\end{array}$} & \multirow[t]{2}{*}{ Age } & \multirow[t]{2}{*}{ Gender } & \multicolumn{2}{|c|}{ Ruler drop test } & \multirow{2}{*}{$\begin{array}{c}\text { Hand-eye } \\
\text { coordination test }\end{array}$} \\
\hline & & & $\begin{array}{c}\text { Non-dominant } \\
\text { hand }\end{array}$ & Dominant hand & \\
\hline Subject 1 & 13 & $\mathrm{~F}$ & 14 & 12 & 11 \\
\hline Subject 2 & 12 & $\mathrm{~F}$ & 22 & 25 & 11 \\
\hline Subject 3 & 12 & $\mathrm{~F}$ & 10 & 11 & 16 \\
\hline Subject 4 & 13 & $M$ & 18 & 17 & 13 \\
\hline Subject 5 & 12 & $\mathrm{~F}$ & 10 & 9 & 13 \\
\hline Subject 6 & 12 & $\mathrm{~F}$ & 14 & 12 & 16 \\
\hline Subject 7 & 12 & $\mathrm{~F}$ & 15 & 11 & 10 \\
\hline Subject 8 & 12 & $\mathrm{~F}$ & 13 & 14 & 18 \\
\hline Subject 9 & 14 & $\mathrm{~F}$ & 10 & 9 & 10 \\
\hline Subject 10 & 13 & $\mathrm{M}$ & 18 & 17 & 12 \\
\hline Subject 11 & 13 & $\mathrm{M}$ & 16 & 12 & 20 \\
\hline Subject 12 & 13 & $\mathrm{M}$ & 12 & 9 & 23 \\
\hline Subject 13 & 13 & $\mathrm{~F}$ & 14 & 10 & 19 \\
\hline Subject 14 & 13 & $\mathrm{~F}$ & 15 & 15 & 18 \\
\hline Subject 15 & 13 & $\mathrm{M}$ & 14 & 10 & 15 \\
\hline Subject 16 & 14 & $\mathrm{M}$ & 17 & 17 & 17 \\
\hline Subject 17 & 13 & $\mathrm{M}$ & 15 & 10 & 12 \\
\hline Subject 18 & 14 & $\mathrm{M}$ & 15 & 13 & 14 \\
\hline Subject 19 & 14 & $\mathrm{~F}$ & 9 & 5 & 20 \\
\hline Subject 20 & 15 & $\mathrm{M}$ & 16 & 15 & 17 \\
\hline Aritmetic Mean & 13 & - & 14.35 & 12.65 & 12.25 \\
\hline
\end{tabular}

\section{Statistical analysis of the results}

The statistical analysis included elements of descriptive statistics (frequency, percentage, mean, median, standard deviation, correlation coefficient, and 95\% confidence interval) and elements of inferential statistics. The Shapiro-Wilk test was applied to determine the distribution of the analyzed data series. 
Table 5. Statistical interpretation of the two tests

\begin{tabular}{|l|c|l|}
\hline Statistical parameters & Average \pm Standard Deviation & Median \\
\hline Age & $13.00 \pm 0.8584$ & 13.00 \\
\hline Height & $1.627 \pm 0.1026$ & 1.615 \\
\hline Weight & $56.15 \pm 17.33$ & 52.00 \\
\hline Ruler drop test-non-dominant hand & $14.35 \pm 3.183$ & 14.50 \\
\hline Ruler drop test-dominant hand & $12.65 \pm 4.283$ & 12.00 \\
\hline Hand-eye coordination test & $15.25 \pm 3.740$ & 15.50 \\
\hline
\end{tabular}

Table 6. The frequency of the results

\begin{tabular}{|l|l|c|c|}
\hline \multicolumn{2}{|l|}{} & Frequency & Percent \\
\hline \multirow{4}{*}{ Class } & V & 3 & $15 \%$ \\
\cline { 2 - 4 } & VI & 5 & $25 \%$ \\
\cline { 2 - 4 } & VII & 10 & $50 \%$ \\
\cline { 2 - 4 } & VIII & 2 & $10 \%$ \\
\hline \multirow{3}{*}{ Gender } & Female & 11 & $55 \%$ \\
\cline { 2 - 4 } & Male & 9 & $45 \%$ \\
\hline \multirow{2}{*}{ Dominant hand } & Right & 18 & $90 \%$ \\
\cline { 2 - 4 } & Left & 2 & $10 \%$ \\
\hline \multirow{2}{*}{ Dominant eye } & Right & 13 & $65 \%$ \\
\cline { 2 - 4 } & Left & 7 & $35 \%$ \\
\hline
\end{tabular}

Table 7. Statistical comparison between dominant hand and non-dominant hand in the ruler drop test

\begin{tabular}{|c|c|c|c|}
\hline Non-dominant/dominant hand. & Non-dominant hand & Dominant hand & Value of $p$ \\
\hline Ruler drop test & $14.35 \pm 3.183$ & $12.65 \pm 4.283$ & 0.0019 \\
\hline Dominant right eye/dominant left eye & Dominant right eye & Dominant left eye & Value of $p$ \\
\hline Ruler drop test-non-dominant hand & $13.77 \pm 3.113$ & $15.43 \pm 3.259$ & 0.2778 \\
\hline Ruler drop test-dominant hand & $12.08 \pm 3.523$ & $13.71 \pm 5.589$ & 0.7801 \\
\hline Hand-eye coordination test & $15.54 \pm 3.382$ & $14.71 \pm 4.572$ & 0.6509 \\
\hline Gender comparison & Female gender & Male gender & Value of $p$ \\
\hline Ruler drop test-non-dominant hand & $13.27 \pm 3.663$ & $15.67 \pm 1.936$ & 0.0289 \\
\hline Ruler drop test-dominant hand & $12.09 \pm 5.049$ & $13.33 \pm 3.279$ & 0.3025 \\
\hline Hand-eye coordination test & $14.73 \pm 3.823$ & $15.89 \pm 3.756$ & 0.5044 \\
\hline Age comparison & r Coefficient & $\begin{array}{l}\text { Interval of } \\
\text { confidence }\end{array}$ & Value of $p$ \\
\hline Ruler drop test-non-dominant hand & -0.01926 & -0.4580 to 0.4270 & 0.9358 \\
\hline Ruler drop test-dominant hand & -0.1145 & -0.5303 to 0.3456 & 0.6307 \\
\hline Hand-eye coordination test & 0.1803 & -0.2850 to 0.5769 & 0.4467 \\
\hline Height comparison & r Coefficient & $\begin{array}{l}\text { Interval of } \\
\text { confidence }\end{array}$ & Value of $p$ \\
\hline Ruler drop test-non-dominant hand & -0.1266 & -0.5390 to 0.3348 & 0.5949 \\
\hline Ruler drop test-dominant hand & -0.2029 & -0.5923 to 0.2633 & 0.3909 \\
\hline Hand-eye coordination test & 0.3274 & -0.1347 to 0.6726 & 0.1588 \\
\hline Weight comparison & r Coefficient & $\begin{array}{l}\text { Interval of } \\
\text { confidence }\end{array}$ & Value of $p$ \\
\hline Ruler drop test-non-dominant hand & -0.06684 & -0.4948 to 0.3872 & 0.7795 \\
\hline Ruler drop test-dominant hand & -0.01131 & -0.4517 to 0.4335 & 0.9623 \\
\hline Hand-eye coordination test & 0.2861 & -0.1792 to 0.6468 & 0.2214 \\
\hline
\end{tabular}


The next phase of the research was to statistically compare the medians of the sample, considering non-dominant hand/dominant hand, dominant eye right/dominant eye left, gender comparison, age comparison, height comparison, and weight comparison.

Using the t-student test for paired data, for the ruler drop test dominant vs. nondominant hand, $\mathrm{p}<0.05$, it was observed that there was a statistically significant difference ( $p=0.0019)$ between the mean values in the ruler drop test in the two groups.

Another statistically significant difference was found using the t-student test for paired data, for the ruler drop test non-dominant hand comparing males to females ( $p=0.0289$ ) between the mean values in the ruler drop test 2 groups.

No other statistical difference was found in the non-dominant hand/dominant hand, dominant eye right/dominant eye left, gender comparison, age comparison, height comparison, and weight comparison for the ruler drop test non-dominant hand, Ruler drop-dominant hand in hand-eye coordination test.

\section{Discussion}

In these experiments, the subjects were asked to catch a tennis ball moving towards them. These conditions are more natural than some experimental protocols because the subjects intercepted an unpredictable moving target and started their free-will movement. Our analysis focuses on the coordination model of eye and hand movement in this task, predicting the degree of target movement and the factors that determine the initiation of interception (Mrotek and Soechting, 2007).

Improved hand-eye coordination (EHC) is associated with greater participation in physical activity. No longitudinal study examined the change in discarded-captured EHC from childhood to adolescence. We investigated the development of EHC with a control test of objects from childhood to midadolescence in boys and girls. Rated at 8, 10, 12, and 16 years of age, EHC is measured as the overall success rate of the wall capture test. The test includes 40 trials of increasing difficulty, determined by the increase in distance from the wall and the transition from catching the ball with both hands to catching the ball with one hand. The results are processed and modeled by generalized linear mixed logistic regression analysis. EHC improves with age, from childhood to midadolescence, although boys are better at every age group ( $p<0.001)$. Models of change in EHC with increasing age varied depending on the degree of pregnancy difficulty $(\mathrm{p}<0.001)$; the skill of throwing and catching with both hands develops earlier than throwing and catching with one hand in both sexes. EHC for boys was better than for girls from 8 , and male competence was maintained until midadolescence. The competence of two-handed throwing and catch rates has developed faster than one-handed throwing rates for both sexes (Lenon et al., 2015).

Our experiments show that people make the same kinds of compromises made in the visual routines model. When pouring the coffee, the subjects stop at a fixed distance from the top of the cup and have minimal deviations between the level in successive fillings, suggesting the use of standard procedures. Also, as our model shows, most of this variance can be explained as noise in an image matching process. In making sandwiches, subjects present very similar ordering tasks so that 
their performance can be easily captured by a decision-making process based on behavioral routines that contain alternative ordering tasks (Yi and Ballard, 2009).

Often used in high schools and colleges as a portion of a pack of sports performance assessment tests, the ruler drop test needs the sportsman to grab the falling ruler; then the clinician calculates the dimension or range of the ruler traveled when caught to provide a simple measure of clinical response time. The clinical utility of the ruler drop test has been previously studied. The researchers confirmed that this clinical reaction time test could be part of a multifaceted contusion assessment battery and a possible way to track recovery from a head injury. The ruler drop test has an acceptable test-retest reliability, which compares favorably with computerized reaction time measures.

The simple reaction time decreased (i.e., improved) after repeated evaluations, and the foremost pronounced improvement happened between the primary two test sessions. Between the first and second tests, the reaction time was reduced by almost seven milliseconds; the overall enhancement among the first and tenth meetings was nearly 13 milliseconds. To some extent, these data are parallel to the data reported in the previous study: between the initial and subsequently modified ruler drop tests, the simple reaction time improved by approximately 11 milliseconds. Unfortunately, based on the data of the 2 test phases alone, researchers cannot determine whether the reaction time will continue to improve with additional exposure (Eckner et al., 2011).

All experiment investigations possess restrictions that affect the generality of the results due to the methods used. The various methodological limitations of our investigation include the fact that participants were not questioned at all during the study about their motivation levels. According to reports, the ruler drop test is an essentially motivational task, and we assume that the motivation level remains constant throughout the research process. In addition, we did not control or monitor participants' diets, fatigue levels, or amount of sleep, all of which are known to affect reaction time (Cote et al., 2009; Hernandez et al., 2007; Jauch-Chara et al., 2010; Van den Berg and Neely, 2006).

In summary, the ruler drop test is easily affected by practice; therefore, practitioners who use this test for diagnostic purposes or pursuit recovery after concussions should consider taking at least one practice session before determining the patient's baseline (Del Rosi et al., 2014).

Our hands are essential tools for our daily lives, and we can use them with grace and skill. To do this, we need to bring them to the right place at the right time. The example of catching a ball can illustrate this. The hand must be positioned at the meeting point at exactly the right time to catch the ball successfully. Moreover, she must be ready for the catch, with her fingers closing around the ball before the moment of contact, or she will not be able to catch it. Too, the level of physical and useful improvement of children (Szabo and Sopa, 2020a; Szabo and Sopa, 2020b; Szabo and Sopa, 2020c) is an important aspect in improving eye-hand coordination, reaction speed, agility, balance and motor abilities in general (Pomohaci and Sopa, 2017a; Pomohaci and Sopa, 2017b; Sopa and Pomohaci, 2017; Sopa and Pomohaci, 2018a; Sopa and Pomohaci, 2018b). 
If the speed of the hand during a touching motion is plotted as a function of time, it can be seen that the tangential velocity curve is bell-shaped. The touch of the movement is continuous with a single top speed. In the last part of the touch movement, the speed is lower when the hand is close to the target. This indicates that the touch movement is programmed before the onset of the high-level movement (Brigit, 2006).

\section{Conclusions}

The differences observed in the research, based on statistics, indicate that significant results were obtained when comparing the dominant hand with the nondominant one, confirming the hypothesis regarding the agility of the dominant hand. Another aspect of significant significance is given by the differences between the genders, the female having a higher reaction speed when using the non-dominant hand than the males.

Finally, although we found that the reaction time data started to apply after the first test session, it remains unclear how long the effects of the practice persist. Therefore, future researchers should try to determine whether there is a limit to how long the effects of the practice are maintained.

\section{References}

Bakhtiar, S., Famelia, R. (2018). Institute Role of Teachers' Education in Improving the Standard of Development Achievement Rate and Standard of Teacher and Education Personnels of Early Childhood Education, 33-45.

Brigit, R. (2006). Chapter 5-Reaching and Eye-Hand Coordination, Hand Function in the Child (Second Edition) Foundations for Remediation, 89-99.

Coleman, R., Piek, J.P., \& Livesey, D.J. (2001). A longitudinal study of motor ability and kinaesthetic acuity in young children at risk of developmental coordination disorder. Human movement science, 20(1-2), 95-110. https://doi.org/10.1016/s0167-9457(01)00030-6

Cote, K.A., Milner, C.E., Smith, B.A., Aubin, A.J., Greason, T.A., Cuthbert, B.P., ... \& Duffus, S.E. (2009). CNS arousal and neurobehavioral performance in a short-term sleep restriction paradigm. Journal of sleep research, 18(3), 291-303. https://doi.org/10.1111/i.1365-2869.2008.00733.x

Davis, B. et al. (2000). Physical Education and the study of sport. 4th ed. London: Harcourt Publishers. p. 130.

Del Rossi, G., Malaguti, A., \& Del Rossi, S. (2014). Practice effects associated with repeated assessment of a clinical test of reaction time. Journal of athletic training, 49(3), 356-359. https://doi.org/10.4085/1062-6059-49.2.04

Eckner, J.T., Kutcher, J.S., \& Richardson, J.K. (2011). Between-seasons test-retest reliability of clinically measured reaction time in National Collegiate Athletic Association Division I athletes. Journal of athletic training, 46(4), 409-414. https://doi.org/10.4085/1062-6050-46.4.409

Ellison, P.H. (2015). Eye-hand Coordination: An Exploration of Measurement and Different Training Methods Using the SVTTM [doctoral dissertation]. Ormskirk, UK: Edge Hill University.

Erickson, G.B. (2007). Sports Vision: Vision Care for the Enhancement of Sports Performance. St. Louis, MO: Butterworth-Heinemann Elsevier.

Goble, D. J., Hurvitz, E.A., \& Brown, S.H. (2009). Deficits in the ability to use proprioceptive feedback in children with hemiplegic cerebral palsy. International Journal of Rehabilitation Research, 32(3), 267-269. https://doi.org/10.1097/MRR.0b013e32832a62d5

Hernández, O.H., Vogel-Sprott, M., \& Ke-Aznar, V.I. (2007). Alcohol impairs the cognitive component of reaction time to an omitted stimulus: a replication and an extension. Journal of studies on alcohol and drugs, 68(2), 276-281. https://doi.org/10.15288/jsad.2007.68.276 
Holst-Wolf, J.M., Yeh, I., \& Konczak, J. (2016). Development of proprioceptive acuity in typically developing children: normative data on forearm position sense. Frontiers in human neuroscience, 10, 436. https://doi.org/10.3389/fnhum.2016.00436

Jauch-Chara, K., Hallschmid, M., Schmid, S.M., Bandorf, N., Born, J., Schultes, B. (2010). Sleep loss does not aggravate the deteriorating effect of hypoglycemia on neurocognitive function in healthy $\begin{array}{llll}\text { men. } & \text { Psychoneuroendocrinology, 35(4), 624-628. }\end{array}$ https://doi.org/10.1016/j.psyneuen.2009.09.018

Kim, O.J. (2001). Development of neurophysiology in the early twentieth century: Charles Scott Sherrington and The Integrative action of the nervous system. Uisahak, 10(1), 1-21.

Konczak, J., Corcos, D.M., Horak, F., Poizner, H., Shapiro, M., Tuite, P., ... \& Maschke, M. (2009). Proprioception and motor control in Parkinson's disease. Journal of motor behavior, 41(6), 543552. https://doi.org/10.3200/35-09-002

Laby, D.M., Kirschen, D.G., Govindarajulu, U., DeLand, P. (2018). The hand-eye coordination of professional baseball players: the relationship to batting. Optom Vis Sci, 95(7), 557-567.

Lennon, J.W., Rohan, M.T., Ross, B.C. (2015). Longitudinal patterns of change in eye-hand coordination in children aged 8-16 years. Human Movement Science, 43, 61-66. https://doi.org/10.1016/i.humov.2015.07.002

Lephart, S.M., Pincivero, D.M., Giraldo, J.L., Fu, F.H. (1997). The role of proprioception in the management and rehabilitation of athletic injuries. Am J Sports Med., 25(1), 130-137. https://doi.org/10.1177/036354659702500126

Li, K.Y., Su, W.J., Fu, H.W., \& Pickett, K.A. (2015). Kinesthetic deficit in children with developmental coordination disorder. Research in developmental disabilities, 38, 125-133. https://doi.org/10.1111/j.1365-2214.2012.01379.x

Mackenzie, B. (2009). Hand Eye Coordination Test [WWW] Available from: https://www.brianmac.co.uk/handeye.htm [Accessed 1/10/2021]

Mackenzie, B. (2004) Ruler Drop Test [WWW] Available from: https://www.brianmac.co.uk/rulerdrop.htm [Accessed 1/10/2021]

Mrotek, L.A., Soechting, J.F. (2007). Target interception: hand-eye coordination and strategies. The Journal of neuroscience: the official journal of the Society for Neuroscience, 27(27), 7297-7309. https://doi.org/10.1523/INEUROSCI.2046-07.2007

Myers, J. B., Guskiewicz, K.M., Schneider, R.A., Prentice, W.E. (1999). Proprioception and Neuromuscular Control of the Shoulder after Muscle Fatigue. J Athl Train, 34(4), 362-367.

Pomohaci, M., Sopa, I.S. (2017a). The utility of motor activities in developing coordonation and mobility at students. Academia Navala "Mircea cel Batran" Scientific Bulletin, 20(2), 57-66.

Pomohaci, M., Sopa, I.S. (2017b). The utility of motor evaluation in the analysis of effects of motor activities on students. Academia Fortelor Terestre" Nicolae Balcescu" din Sibiu, Revistă Stiintifică, 22(3), 163-172.

Ribeiro, F., Oliveira, J. (2007). Aging effects on joint proprioception: the role of physical activity in proprioception preservation. Eur Rev Aging Phys Act., 4(2), 71-76. https://doi.org/10.1007/s11556-007-0026-x

Riemann, B.L., Lephart, S.M. (2002). The Sensorimotor System, Part I: The Physiologic Basis of Functional Joint Stability. J Athl Train., 37(1), 71-79.

Singh, J.P. (2010). United Nations Educational, Scientific, and Cultural Organization (UNESCO): creating norms for a complex world. Routledge, 10-23.

Sopa, I.S., Pomohaci, M. (2017). Study regarding the development of agility skills of students aged between 10 and 12 years old, Timişoara Physical Education and Rehabilitation Journal. The Journal of West University of Timişoara, 9(17), 7. https://doi.org/10.1515/tperj-2016-0009

Sopa, I.S., Pomohaci, M. (2018a). Leisure sport activities and their importance in living a healthy physical and psycho-social lifestyle. Buletinul Academiei Fortelor Terestre "Nicolae Balcescu" Sibiu, 22(1), 36-42.

Sopa, I.S., Pomohaci, M. (2018b). Evaluation of motor development and skills in mini-volleyball game (10-12 years old), Bulletin of the Transilvania University of Brasov Series IX: Science of Human Kinetics, 11(1), 95-104. 
Sopa, I.S., Pomohaci, M. (2021). Using coaching techniques in assessing and developing the static and dynamic balance level of young volleyball players. Bulletin of the Transilvania University Brasov, 14(63), 89-100. https://doi.org/10.31926/but.shk.2021.14.63.1.12

Szabo, D.A., Sopa, I.S. (2020a). Study regarding the level of physical and functional development of children from primary school level. Journal of Physical Education and Sport (JPES) Pitești, 20(3), 1479-1504.

Szabo, D.A., Sopa, I.S. (2020b). Study regarding the level of bio-motor and health of children from gymnasium level. Sport si Societate, Interdisciplinary Journal of Physical Education and Sports Iași, 20.1(1), 1-9.

Szabo, D. A., Sopa, I. S. (2020c). Research regarding development and evaluation of agility (balance, coordination and speed) in children aged 9-10 years. Health, Sports \& Rehabilitation Medicine Cluj, 21(1), 33-40.

Szabo, D.A., Neagu, N., Teodorescu, S., Sopa, I.S. (2020). Eye-hand relationship of proprioceptive motor control and coordination in children 10-12 years old. Health, Sports \& Rehabilitation Medicine Cluj, 21(3), 185-191.

Szabo, D.A., Neagu, N., Teodorescu, S., Panait, C.M., \& Sopa, I.S. (2021). Study on the Influence of Proprioceptive Control versus Visual Control on Reaction Speed, Hand Coordination, and Lower Limb Balance in Young Students 14-15 Years Old. International Journal of Environmental Research and Public Health, 18(19), 10356. https://doi.org/10.3390/ijerph181910356

Van den Berg, J., Neely, G. (2006). Performance on a simple reaction time task while sleep deprived. Percept Mot Skills, 102(2), 589-599. https://doi.org/10.2466/pms.102.2.589-599

Westlake, K.P., Culham, E.G. (2007). Sensory-specific balance training in older adults: effect on proprioceptive reintegration and cognitive demands. Phys Ther., 87(10), 1274-1283. https://doi.org/10.2522/ptj.20060263

Yi, W., \& Ballard, D. (2009). Recognizing behavior in hand-eye coordination patterns. International $\begin{array}{lllll}\text { journal of } \quad H R \text { : humanoid } & \text { robotics, }\end{array}$ https://doi.org/10.1142/S0219843609001863

Zwicker, J.G.; Harris, S.R.; Klassen, A.F. (2013). Quality of life domains affected in children with developmental coordination disorder: a systematic review. Child Care Health Dev., 39, 562-580. https://doi.org/10.1111/j.1365-2214.2012.01379.x

https://www.brianmac.co.uk/rulerdrop.htm

https://www.topendsports.com/testing/tests/wall-catch.htm

https://nathankanginanpdhpeassignment.weebly.com/hand-wall-toss.html

http://math.oxford.emory.edu/site/home/futurePages/excelProjectReactionTime/ 